\title{
ANALISA KEKUATAN AGREGAT KIAS A MATERIAL KABUPATEN SOLOK
}

\author{
MASRIL \\ Dosen Fakultas Teknik, UMSB \\ mril6030@gmail.com \\ DOI: http://dx.doi.org/10.31869/rtj.v2i2.1440
}

\begin{abstract}
Abstrak: Supaya terwujudnya tujuan dari pembangunan antara suatu wilayah ke wilayah lainnya melalui transportasi darat, maka sangatlah penting dibangunan sarana jalan. Dalam ilmu konstruksi sipil, bahan material yang bisa dipakai sebagai bahan sangat menentukan kwalitas dan kuantitas dari kondtruksi tersebut .

Konstruksi Base atau lapisan pondasi adalah sangat disamping sebagai lapisan pondasi juga untuk memikul beban kendaraan atau lalu lintas yang melewati konstruksi jalan tersebut , Sehingga dibutuh material yang kwalitasnya.

Untuk pelaksanaan perencanaan tebal perkerasan lapisan konstruksi perkerasan perlulah dipertimbangkan seluruh faktor yang dapat mempengaruhi konstruksi jalan seperti, Fungsi jalan, Umur Rencana, Lalulintas, Daya dukung tanah , faktor regional, Indek Permukaan (IP), Angka Ekivalen, Lalu lintas Harian Rata- rata, Indek Tebal Perkerasan dan Koefesien kekuatan Relatif.

Dalam pembuatan konstruksi jalan , material yang digunakan sangat menentukan kwalitas jalan, jadi dalam pelaksanaan pembuataan jalan perlu dilaksanakan pengujian laboratorium, yang mana dalam pengujian labor yang dibahas ini adalah agregat kasar yang berasal dari kabupaten Solok Sumatera B arat, yang nantinya digunakan untuk Base Klas A pada ruas jalan. Adapun pelaksanaan Pengujian yang penulis dilaksanakan adalah perhitungan proporsi agregat base Klas A,Berat jenis Agregat,Pengujian pemadatan campuran agregat Base Kla A ,Pengujian CBR laboratorium , Dan penentuan CBR Rencana.

Hasil pengujian didapat bisa menjadi rekomendasi apakah agregat tersebut bisa dipakai atau tidak. Hasil Pengujian laboratorium didapat adalah Dari hasil Pengujian terhadapat agregat Klas A yang material yang berasal dari solok adalah Pengujian proporsi agregat base A memenuhi persayaratan karena yakni masuk saringan 2" sampai saringan 200 , Pengujian Berat jenis agregat didapat berat jenis 2,685,Pengujian pemadatan agregat didapat Berat Isi $=2,763 \%$ dan Kadar air Optimum $=5,75 \%$. Dari nilai hasil pengujian diatas dapat diambil kesimpulan bahwasanya agregat kasar yang berasal dari Solok tersebut bisa digunakan untuk Base Klas A pada pekerjaan konstruksi Jalan
\end{abstract}

\section{Kata Kunci : Agregat Base Klas A untuk Jalan}

Abstract: In order to realize the goal of development between an area to another region through land transportation, it is very important in the construction of road facilities. In civil construction science, material that can be used as material greatly determines the quality and quantity of the construction.

Base construction or foundation layer is very besides as a foundation layer also to bear the burden of vehicles or traffic that passes through the construction of the road, so that material is needed quality.

For the implementation of planning for pavement thickness of pavement construction layers, it is necessary to consider all the factors that can affect road construction such as road function, age of plan, traffic, carrying capacity of land, regional factors, surface index (IP), equivalent numbers, average daily traffic, Pavement Thickness Index and Relative strength Coefficient.

In making road construction, the material used determines the quality of the road, so in the implementation of road construction it is necessary to carry out laboratory testing, which in the labor test discussed is coarse aggregates originating from Solok Sumatra B arat district, which will later be used for Base Class A on the road. The implementation of the Tests that the authors carried out was the calculation of the aggregate class A class proportion, Aggregate Specific Gravity, Compaction Test of the Base Class A aggregate mixture, Laboratory CBR Testing, and CBR Plan determination. 
The test results obtained can be a recommendation whether or not the aggregate can be used. Laboratory test results were obtained from the results of the testing of aggregate Class A material derived from solok. Testing the aggregate proportion of base A meets the requirements because it enters the filter 2 "to filter 200, Testing the aggregate density obtained density 2,685, Testing for aggregate compaction obtained Weight Content $=2.763 \%$ and Optimum moisture content $=5.75 \%$. From the value of the above test results it can be concluded that the coarse aggregates originating from Solok can be used for Base Class A on Road construction work

Keywords : Aggregate Base Class A for Roads

\section{PENDAHULUAN}

\section{A . Latar Belakang}

Agregat kls A sebagai bahan konstruksi sudah lama dikenal secara luas dalam pembuatan jalan . penggunaan pun di Indonesia .infrastrutur jalan dapat dikatakan baik apabila dalam pemakaiannya dapat sesuai dengan umur rencana yang direncanakan . maka agregat Klas A Merupakan suatu bahan Utama dalam pembauatan Pondasi atas Pada Jalan maka bahan tersebut harus tahan terhadap beban yang bekerja diatasnya nanti

\section{B . Rumusan Masalah}

Rumusan dalam Penelitiaan ini adalah bagaimana cara pengujian yang dilakasanakan dilaboratorium agar agregat Klas A Berasal dari Solok ,memenuhi standar perencanaan dan pengujian yang dilaksanakan tersebut adalah perhitungan proporsi agregat base Klas A, Berat jenis Agregat,Pengujian pemadatan campuran agregat Base Kla A ,Pengujian CBR laboratorium, Dan penentuan CBR Rencana.

\section{C.Maksud dan Tujuan Penelitian}

Maksud dari penulisan ini agar kita mengetahui dan pengujian yang dilaksanakan tersebut adalah perhitungan proporsi agregat base Klas A,Berat jenis Agregat,Pengujian pemadatan campuran agregat Base Kla A ,Pengujian CBR laboratorium, Dan penentuan CBR Rencana.

Tujuan dari penelitian ini adalah Menganalisa kekuatan material Base Klas A yang berasal dari Ujung Batu apakah memenuhi standart atau tidak.

\section{Ruang Lingkup/Batasan Penelitian}

Dalam menganalisa Material Klas A yang berasal dari Solok penulis membatasi masalah yang akan dibahas pada penelitian ini adalah perhitungan proporsi agregat base Klas A,Berat jenis Agregat,Pengujian pemadatan campuran agregat Base Kla A,Pengujian CBR laboratorium, Dan penentuan CBR Rencana.

\section{KAJIAN PUSTAKA}

Lapis perkerasan yang terletak diantara lapis pondasi bawah dan lapis permukaan dinamakan lapis pondasi atas (base course).

Fungsi lapis pondasi atas ini antara lain sebagai berikut :

- Sebagai perkerasan yang menahan gaya lintang dari beban roda dan menyebarkan beban ke lapisan pondasi bawah.

-Lapisan persiapan untuk lapisan pondasi bawah

-Bantalan terhadap lapisan permukaan

Material yang digunakan untuk lapisan pondasi atas adalah material yang cukup kuat dan untuk pondasi atas tanpa bahan pengikat digunakan agregat kelas $\mathrm{A}$

Sebagai lapis pondasi atas yang akan memikul beban lalu lintas dan meneruskan ke lapis pondasi bawah, maka kualitas agragat adalah merupaka factor yang sangat penting. Untuk itu agar memenuhi persyaratan laboratorium, sehingga diketahui mutu agregat yang akan dipergunakan dan pengujian tersebut antara lain adalah sebagai berikut:

a. Gradasi dan ukuran butir

Syarat utama campuran agregat sebagai bahan konstruksi perkerasan jalan adalah gradasi yang dipakai akan menentukan kestabilan konstruksi jalan.

Pada garis besarnya ada 3 (tiga) macam campuran agregat yaitu :

- Gradasi menerus (butir-butir halus mengisi pori-pori secara cukup), campuran ini mempunyai stabilitas tinggi, karena adanya interlocking yang baik antara agregat. Kekuatan diperoleh dari kotak antara butir dan stabilitas bisa ditingkatkan dari sifatsifat kohesi butir halus yang mengisi void (ruang). 
- Gradasi timpang (Gap graded)

Sebagian ukuran butir hampir seragam, mempunyai sifat kurang stabil dan kurang kedap karena terdapat ruang antar agregat. Gradasi jenis ini lebih sesuai untuk agregat campuran hot rolled shet (HRS), karena mempunyai cukup ruang untuk bitumen.

- Gradasi seragam (Uniform graded) Mempunyai ukuran butir yang sama, tidak stabil dan kekuatan diperoleh dari kontak antar butir.

b. Kekerasan / Keausan (strength and tougness)

Pada pekerjaan jalan, sebelum agregat mengalami proses pemecahan penghancuran dan penghalusan baik waktu crushing maupun pada waktu penghamparan dan pemadatan. Begitu pula halnya pada waktu agregat menerima beban lalu lintas, jika sifat kekerasan agregat tidak dipenuhi maka agregat bisa pecah dan jika hal ini terjaadi maka konstruksi perkerasan yang telah direncanakan tidak bisa mencapai umur rencana.

Pengujian ketahanan terhadap keausan di laboratorium dilakukan dengan mesin pengaus Los Angeles abrasion machine.

c. Ketahanan tarhadap pelapukan (soundness)

Pengaruh cuaca terhadap agregat sebagai bahan perkerasan akan menimbulkan pelapukan (weathering) begitu pula pengaruh kondisi lingkungan. Akibat konstruksi tidka awet / tahan, gradasi agregat berubah sehingga konstruksi perkerasan tidak stabil.

d. Tekstur permukaan

Susunan permukaan yang kasar akan mempunyai kecenderungan nambah kekuatan campuran bila dibandingkan dengan permukaan yang licin dan permukaan yang kasar akan menimbulknan ikatan yang baik antara butiran dan akan menimbulkan ikatan yang baik pula terhadap agregat dan bitumen yang kasar umumnya akan meningkatkan stabilitas dan keawetandalam campuran butimen. e. Bentuk butiran

Bentuk butiran akan mempunyai beberapa pengaruh terhadap konstruksi perkerasan, terutama berpengaruh terhadap kemampuan pemadatan.

Bentuk butiran yang bulat / lonjong kurang membentuk bidang kontak antara agregat karena bidang sentuhnya hanya merupakan garis singgung atau titik, $\mathrm{s}$ ehingga terdapat ruang antara yang besar. Bentuk butiran yang pipih mempunyai peluang akan berubah bentuk butiran yang baik berbentuk kubus. Dalam pelaksanaan, batasan penggunaan bentuk butiran dipertimbangkan antara lain sebagai berikut :

- Untuk lapis pondasi bawah, bentuk butiran bulat masih bisa dapat dipergunakan.

- Untuk lapis pondasi entuk butiran bulat masih ada digunakan dengan batasan $40 \%$ agregat bulat tersebut minimal mempunyai satu bidang pecah.

- Untuk lapis permukaan butiran berbentuk bulat tidak diperbolehkan jadi seluruh agregat harus berbentuk kubus / pecah.

f. Absorsi

Pemeriksaan absorsi di laboratorium biasanya dilakukan bersamaan dengan proses pemeriksaan berat jenis.

Absorsi dan berat jenis nilai juga dapat dipakai untuk identifikasi kekuatan / kekerasan suatu agregat. Jika dibandingkan dengan sifat-sifat agregat lainnya maka absorsi tidak terlalu besar pengaruhnya tehadap kekuatan, tetapi berpengaruh dalam segi ekonomisnya apabila digunakan dalam campuran aspal beton.

Maksudnya adalah apabila absorsi besar maka aspal yang diserap oleh agregat tersebut akan menjadi besar pula sehingga diperlukan pemakaian aspal yang besar

g. Kebersihan

Agregat yang akan dipergunakan untuk konstrukai perkerasan harus bersih dari bahan-bahan kotoran yang tidak dikehandaki yang dapat merugikan campuran perkerasan itu sendiri hal ini dalam persyaratan dibatasi. 
Kebersihan agregat sering dapat ditentukan dengan pemerikasaan secara visual sedangkan di laboratorium digunakan dengan metode sand equivalent test, yang merupakan perbandingan relatif antara bagian yang merugikan terhadap agregat yang lolos saringan No. 4

h. Berat jenis

Penentuan berat jenis ini terutama dipergunakan untuk campuran aspal beton, untuk campuran agregat tanpa bitumen berat jenis tidak terlalu penting. Batasanbasatasan yang harus dipenuhi oleh agregat kelas A adalah sebagai berikut :

- Fraksi agregat kasar yang lolos ayakan $50 \mathrm{~mm}$ dana tertahan ayakan $4,75 \mathrm{~mm}$ harus terdiri dari partikel yang keras, awet dan jika dihasilkan dari kerikil maka tidak kurang dari $50 \%$ berat agregat harus terdiri partikel yang memiliki paling sedikit satu muka bekas pecahan dan jika kelebihan butir halus kerikil tersebut harus diayak.

- Fraksi agregat halus

Agregat halus yang lolos ayakan 4,75 $\mathrm{mm}$ harus terdiri dari pertikel pasir alami atau pasir pecah serta material halus lainnya.

\section{METODE PENELITIAN}

Penelitian ini dilakukan dalam berbagai tahap, yakni dimulai dari studi literatur. Studi literatur dilakukan dengan mempelajari buku, jurnal serta penelitian terdahulu yang berkaitan dengan topik dalam penelitian ini. Persiapan Alat dan Bahan, dilakukan dengan menentukan alat - alat dan bahan yang dipakai dan sudah harus di siapkan sebelum penelitian dimulai.Pengujian agregat melakukan pengujian proporsi agregat base Klas A,Berat jenis Agregat,Pengujian pemadatan campuran agregat Base Kla A ,Pengujian CBR laboratorium, Dan penentuan CBR Rencana. Dan mempersipakan bahan Agregat kasar Klas A yang berasal dari daerah Ujung Batu

\section{ANALISIS DATA}

Bahan yang akan dianalisa adalah bahan klas A untuk lapisan pondasi atas yang bersal dari daerah Ujung Batu Prpinsi Riau.
Pengujian yang pertama adalah perhitungan proporsi agregat base klas A. Dari data yang diperoleh bahwa untuk pengujian ini agregat kasar ini bisa dipakai karena kita lihat pada hasil grafik perhitungan bahwa garis grafik rata - rata masih berada pada posisi tenahag tengah seperti kita lihat di grafik dibawah ini :

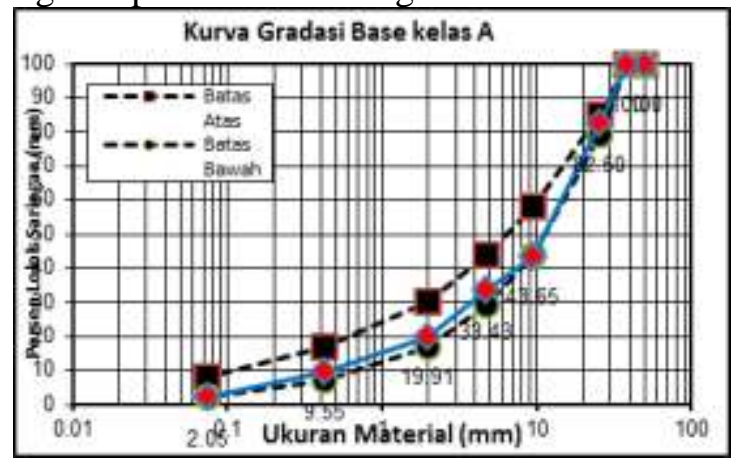

2) Analisa Berat Jenis Agregat Kasar

\begin{tabular}{|c|c|c|c|}
\hline \multicolumn{4}{|c|}{ BERAT JENIS DAN PENYERAPAN AGREGAT } \\
\hline \multirow{2}{*}{\multicolumn{2}{|c|}{$\begin{array}{l}\text { Material Agregat } \\
\text { Tertahan \# N0. } 4 \\
\text { (Prosedur Pengujian : } \\
\text { SNI 03-1969-1990) }\end{array}$}} & \multicolumn{2}{|c|}{ SAMPEL } \\
\hline & & 1 & 2 \\
\hline $\begin{array}{l}\text { Berat } \\
\text { Benda Uji } \\
\text { Kering Oven }\end{array}$ & (BK) & 2485,0 & \\
\hline \begin{tabular}{l}
\multicolumn{1}{c}{ Berat } \\
Benda Uji \\
Kondisi SSD
\end{tabular} & (BJ) & 2523,1 & \\
\hline $\begin{array}{c}\text { Berat } \\
\text { Benda Uji } \\
\text { Dalam Air }\end{array}$ & (BA) & 1559,5 & \\
\hline $\begin{array}{l}\text { Berat Jenis } \\
\text { Bulk }\end{array}$ & $\begin{array}{r}\mathrm{BK} /( \\
\mathrm{BJ}-\mathrm{BA})\end{array}$ & 2,579 & \\
\hline \multicolumn{4}{|l|}{ Rata-Rata } \\
\hline $\begin{array}{l}\text { Berat Jenis } \\
\text { SSD }\end{array}$ & $\begin{array}{c}\mathrm{BJ} /(\mathrm{B} \\
\mathrm{J}-\mathrm{BA})\end{array}$ & 2,618 & \\
\hline \multicolumn{4}{|l|}{ Rata-Rata } \\
\hline $\begin{array}{l}\text { Berat Jenis } \\
\text { App. }\end{array}$ & $\begin{array}{r}\mathrm{BK} /( \\
\mathrm{BK}-\mathrm{BA})\end{array}$ & 2,685 & \\
\hline \multicolumn{4}{|l|}{ Rata-Rata } \\
\hline Absorption & $\begin{array}{r}\text { (BJ- } \\
\text { BK)/BK } \\
\times 100 \%\end{array}$ & 1,533 & \\
\hline
\end{tabular}


Vol. 2 No.2 Juni 2019

http://jurnal.umsb.ac.id/index.php/RANGTEKNIKJOURNAL

Harga CBR

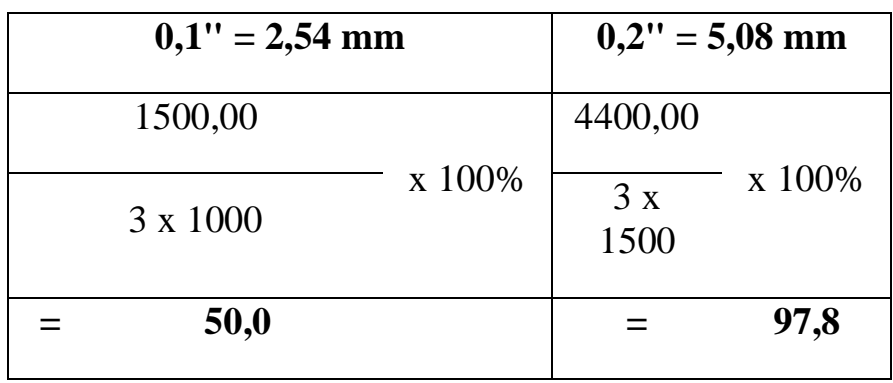

Jadi setelah dilaksanakan pengujian material , berat jenis agregat adalah 2,685.bearti ditinjau dari segi berat jenis agregat bahwa agregat kasar Base Klas A yang berasal dari Solok memenuhi.

3) Pengujian Pemadatan material agregat Kasar base Klas A yang berasal dari Ujung batu:

Dapat dilihat di grafik di bawah ini :

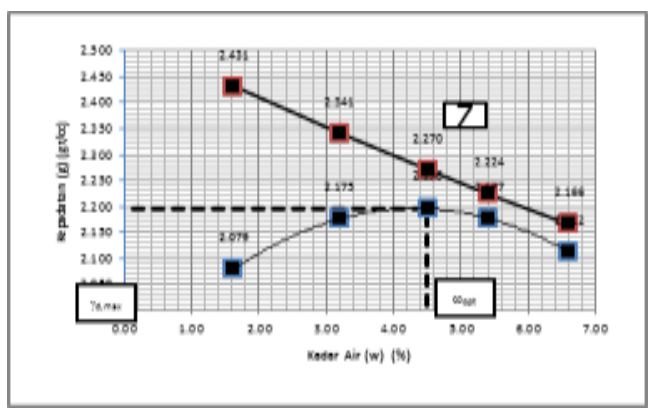

\section{HASIL PENGUJIAN}

Berat isi kering $=2,196 \mathrm{gram} / \mathrm{cc}$ kadar air optimum $=4,5 \%$

Pengujian CBR Laboratorium

a) dengan tumbukan $65 \times 5$

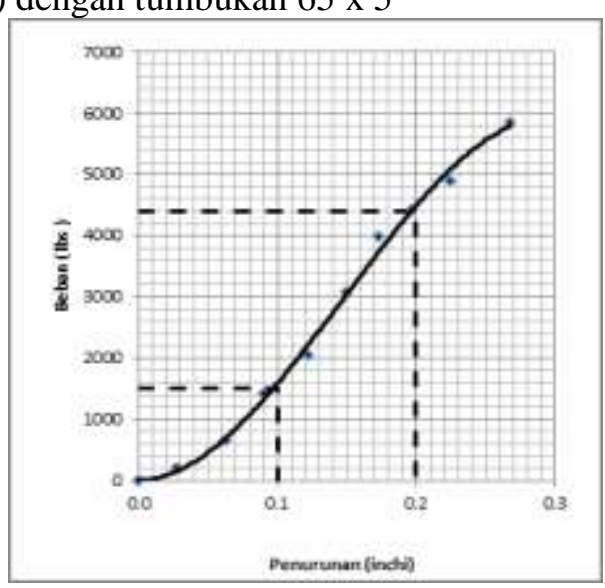

b) dengan tumbukan $30 \times 5$

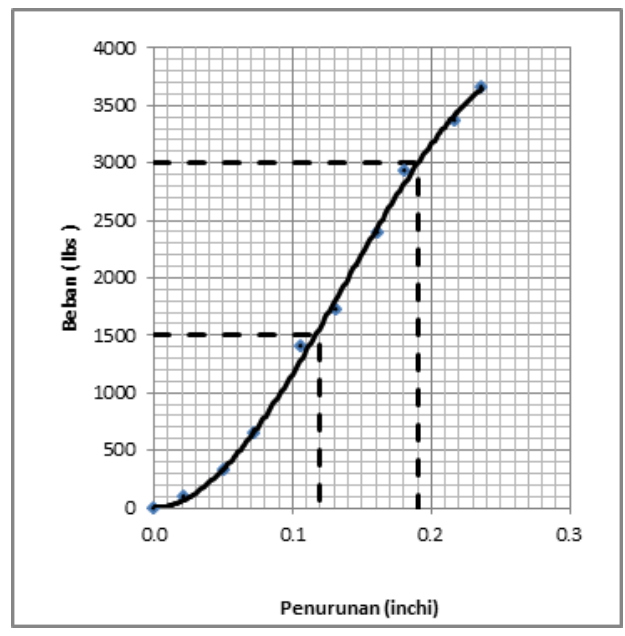

\section{Harga CBR}

\begin{tabular}{|c|c|}
\hline $0,1 "=2,54 \mathrm{~mm}$ & $0,2^{\prime \prime}=5,08 \mathrm{~mm}$ \\
\hline 1500 & 3000 \\
\hline $3 \times 1000$ & $\begin{array}{c}3 \times \\
1500\end{array}$ \\
\hline $\mathbf{5 0 , 0}$ & 66,7 \\
\hline
\end{tabular}

c) dengan tumbukan $10 \times 5$ tumbukan

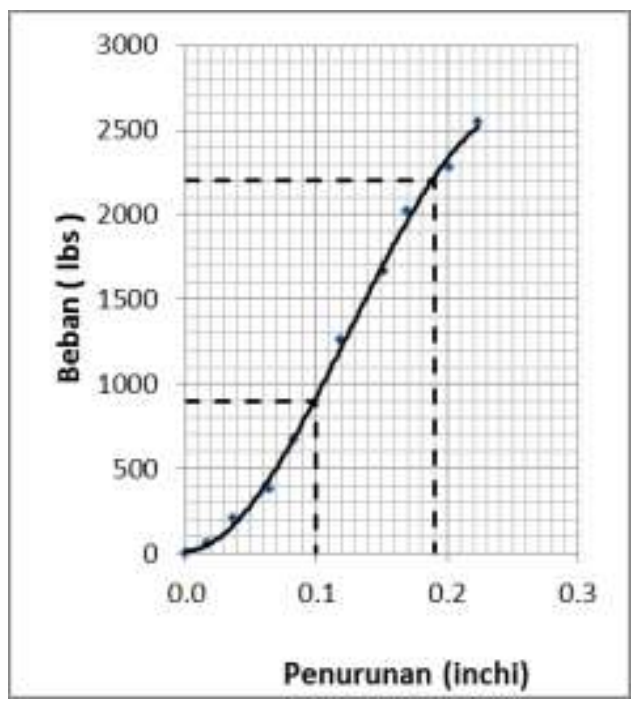


Vol. 2 No.2 Juni 2019

http://jurnal.umsb.ac.id/index.php/RANGTEKNIKJOURNAL

Harga CBR

\begin{tabular}{|c|c|c|c|}
\hline $0,1^{\prime \prime}=2$, & & $0,2^{\prime \prime}=5$ & $8 \mathrm{~mm}$ \\
\hline 900 & \multirow{2}{*}{$\begin{array}{c}\mathrm{x} \\
100 \%\end{array}$} & 2200 & \multirow{2}{*}{ x $100 \%$} \\
\hline $3 \times 1000$ & & $3 \times 1500$ & \\
\hline 30,0 & & $=$ & 48,9 \\
\hline
\end{tabular}

Penentuan nilai CBR Rencana didapat Nilai adalah

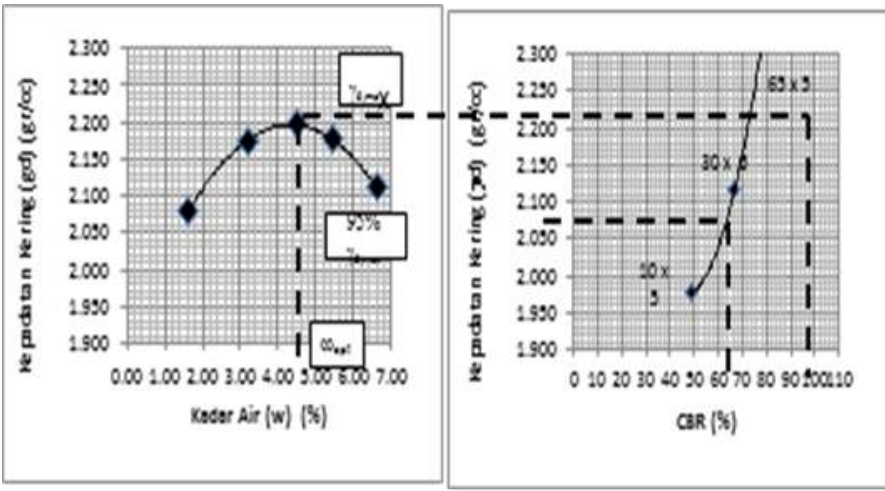

Nilai CBR

Rencana

\begin{tabular}{|c|c|c|}
\hline $\begin{array}{c}\text { CBR pada 100\% } \\
\text { gd }\end{array}$ & 92 & $\%$ \\
\hline $\begin{array}{c}\text { CBR pada 95\% } \\
\text { gd }\end{array}$ & 55 & $\%$ \\
\hline
\end{tabular}

PENUTUP

\section{Simpulan}

Dari hasil Pengujian terhadapat agregat Klas A yang material yang berasal dari Solo maka dalam hal ini bisa diambil kesimpulan adalah :

1) Pengujian proporsi agregat base $A$ memenuhi persayaratan karena yakni masuk saringan 2" sampai saringan 200 .

2) Pengujian Berat jenis agregat didapat berat jenis 2,685.

3) Pengujian pemadatan agregat didapat Berat Isi kering $=2,195 \%$ dan Kadar air Optimum $=4,5 \%$

4) Pengujian CBR Rencana didapat nilai nya CBR $100 \% 100$ gd didapat $92 \%$,CBR $95 \%$ gd didapat $55 \%$
Dari nilai hasil pengujian diatas dapat diambil kesimpulan bahwasanya agregat kasar yang berasal dari Ujung batu tersebut bisa digunakan untuk Base Klas A pada pekerjaan Jalan

\section{Saran - Saran}

Dalam Pelaksanaan pekerjaan pembangunan jalan sebelum menggunakan material baik materaial klas A maupun Klas C, mupun aspal seharusnya Diuji dulu dilaboratorium, agar bisa memenuhi persyaratan Teknis .

\section{DAFTAR PUSTAKA}

Buku Depatemen pekerjaan Umum 1999, "perencanaan campuran beraspal dengan pendekatan Kepadatan Mutlak “,N0 025 ' T/BM/1999 direktorat Jendral Bina Marga.

Sukirman , Silvia ,1992, Perkerasan lentur Jalan Raya, Penerbit Nova Bandung

Sukirman, Silvia 2007, Beton Aspal Campuran panas, Edisi ke 2 Penerbit Obor Indonesia , Jakarta

Sukirman Silvia, 2010 Perencanaan Tebal perkerasan Lentur Penerbit Nova 